\section{Superior dentine tubule occlusion}

Two in-vitro studies provide dental professionals with further evidence of the effectiveness of the PRO-ARGIN technology compared to other technologies on the market.

Colgate SENSITIVE PRO-Relief toothpaste provides superior dentine tubule occlusion when compared with stannous fluoride/ sodium fluoride technology $(91 \% \text { vs. } 67 \%)^{1}$ and novamin/sodium fluoride technology ( $88 \%$ vs. $50 \%){ }^{2}$

Recommend Colgate SENSITIVE PRO-Relief toothpaste to your patients to provide superior dentine tubule occlusion ${ }^{1,2}$ (vs novamin/sodium fluoride technology and stannous fluoride/ sodium fluoride technology $[\mathrm{p}<0.05]$ ) (In-vitro study, actual confocal images after five applications $[\mathrm{p}<0.05])$, an acid resistant layer, ${ }^{3}$ instant (for instant relief, apply directly to the sensitive tooth with fingertip and gently massage for one minute) sensitivity pain relief, ${ }^{4}$ long lasting sensitivity pain relief $^{5}$ and improved patient satisfaction. ${ }^{6,7}$

Visit www.colgateprofessional.co.uk for further information and to watch the superior technology in action.

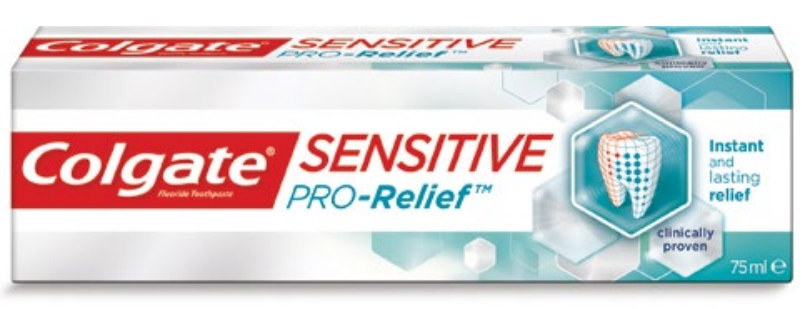

\section{References}

1. Hines D et al. Poster, July 2018 IADR. Colgate-Palmolive Company 2018.

2. Hines D et al. Poster \#0742, March 2018 AADR. Colgate-Palmolive Company 2018.

3. Report Deon Hines-0003, 2016, confocal images after five applications.

4. Nathoo S, Delgado E, Zhang Y P, DeVizio W, Cummins D, Mateo L R. Comparing the efficacy in providing instant relief of dentin hypersensitivity of a new toothpaste containing $8.0 \%$ arginine, calcium carbonate, and $1450 \mathrm{ppm}$ fluoride relative to a benchmark desensitizing toothpaste containing $2 \%$ potassium ion and $1450 \mathrm{ppm}$ fluoride, and to a control toothpaste with $1450 \mathrm{ppm}$ fluoride: a three-day clinical study in New Jersey, USA. J Clin Dent 2009; 20(Spec Iss): 123-130.

5. Docimo R, Montesani L, Maturo P et al. Comparing the efficacy in reducing dentin hypersensitivity of a new toothpaste containing $8.0 \%$ arginine, calcium carbonate, and $1450 \mathrm{ppm}$ fluoride to a commercial sensitive toothpaste containing $2 \%$ potassium ion: an eight-week clinical study in Rome, Italy. J Clin Dent 2009; 20(Spec Iss): 17-22.

6. Ipsos, UK Patient Experience Programme on Colgate Sensitive Pro-ReliefTM, results collected after 2-week trial, 192 respondents, 2016.

7. Gernhardt C R, Poster presented 2016, FDI.

\section{New oral health campaign launched}

A new campaign by Johnson \& Johnson is offering more than 400,000 people up to $£ 50$ off a dental hygiene appointment.

Across England, Wales and Northern Ireland, $66 \%$ of adults have visible plaque and $83 \%$ show some evidence of gum disease, ${ }^{1}$ suggesting that there is still more help needed for the population to achieve better levels of plaque control.

Johnson \& Johnson has been dedicated to supporting dental professionals in improving their patients' oral health for over 100 years, making full use of evidence-based clinical research and science to help deliver better outcomes through its range of LISTERINE mouthwashes.

Building on this, the new campaign aims to offer greater support to dental hygienists, as Johnson \& Johnson recognises the importance of regular dental and hygiene visits and is committed to helping reinforce that message among the public.

With only $17 \%$ of adults from England, Wales and Northern Ireland stating that they had seen a dental hygienist at their last completed course of dental treatment, ${ }^{1}$ it seems that there remains a need for increased awareness and access.

To qualify, the individual must purchase two promotional bottles of LISTERINE, available in Tesco stores from this month. They then visit their existing hygienist or make an appointment with any hygienist in the UK for a scale and polish and pay for the appointment in the usual way, applying to Johnson \& Johnson for reimbursement up to a value of $£ 50$.

The only impact on dental hygienists may be an increase in patient numbers, especially where cost of treatment has previously been a barrier.

www.listerineprofessional.co.uk/dentalcheck.

\section{References}

1. The Health and Social Care Information Centre. Adult Dental Health Survey 2009. 2011.

\section{Interdental brushes made for the individual}

For a patient, finding an interdental brush that is both effective and easy to use can be easier said than done - that's where Curaprox comes in.

There are five different ranges available from the healthcare specialist, each uniquely designed to help patients meet their oral care needs. So whether you have an individual with periodontal problems, an implant patient or someone that simply wants to improve their oral health, Curaprox has the solution that will tick all the boxes.
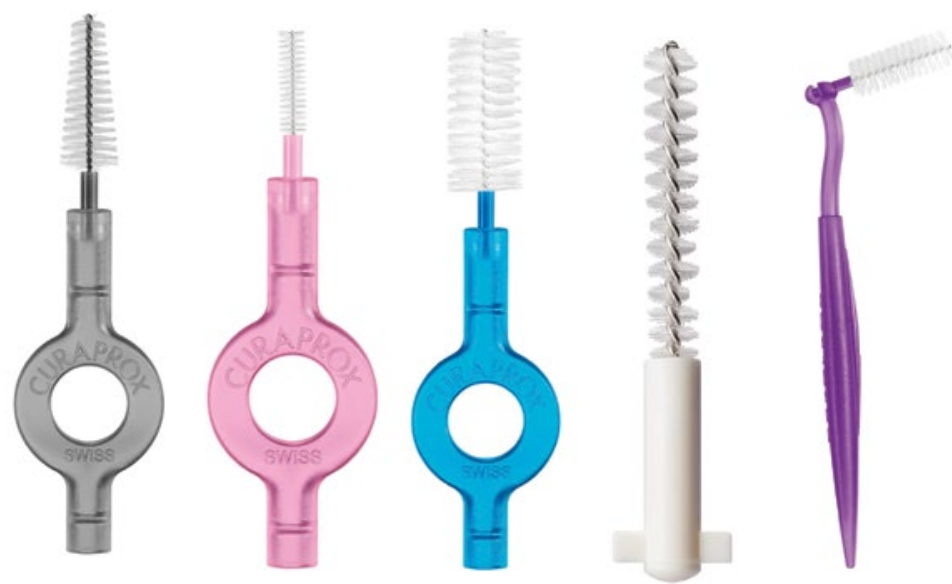

To ensure patients get the most out of Curaprox interdental brushes, the holder can be customised to whatever they find easiest and most comfortable, with options including angled or straight, click or twist-fit and plastic, aluminium or stainless steel.

Do your patients a favour - help them discover Curaprox interdental brushes today.

For more information call 01480 862084, email info@curaprox. co.uk or visit www.curaprox.co.uk. 